\title{
Animal models in peritoneal dialysis
}

\author{
Olga Nikitidou ${ }^{1}$, Vasiliki I. Peppa ${ }^{2}$, Konstantinos Leivaditis ${ }^{1}$, Theodoros Eleftheriadis ${ }^{1}$, \\ Sotirios G. Zarogiannis ${ }^{2}$ and Vassilios Liakopoulos ${ }^{1 *}$
}

${ }^{1}$ Division of Nephrology and Hypertension, 1 st Department of Internal Medicine, School of Medicine, American Hellenic Educational Progressive Association Hospital, Aristotle University of Thessaloniki, Thessaloniki, Greece, ${ }^{2}$ Department of Physiology, Faculty of Medicine, BIOPOLIS, University of Thessaly, Larissa, Greece

Peritoneal dialysis (PD) has been extensively used over the past years as a method of kidney replacement therapy for patients with end stage renal disease (ESRD). In an attempt to better understand the properties of the peritoneal membrane and the mechanisms involved in major complications associated with PD, such as inflammation, peritonitis and peritoneal injury, both in vivo and ex vivo animal models have been used. The aim of the present review is to briefly describe the animal models that have been used, and comment on the main problems encountered while working with these models. Moreover, the differences characterizing these animal models, as well as, the differences with humans are highlighted. Finally, it is suggested that the use of standardized protocols is a necessity in order to take full advantage of animal models, extrapolate their results in humans, overcome the problems related to PD and help promote its use.

Keywords: animal models, ion and water transport, membrane physiology, peritoneal dialysis, ussing chamber

Peritoneal dialysis (PD) is a well-established method of kidney replacement therapy. It is currently estimated that the end stage renal disease (ESRD) patients receiving PD worldwide are approximately 200,000 and that they represent $11 \%$ of the total number of patients receiving any modality of dialysis (Jain et al., 2012). It is worth mentioning that Putman in 1923 made the first attempt for PD in a canine model (Putnam, 1923).

The extended use of PD over the years makes the in depth understanding of the physiology of the peritoneal membrane, the transport of solute and water across it and the mechanisms influencing inflammation, peritonitis, peritoneal injury and encapsulating peritonitis, a necessity. Moreover, many therapeutic interventions, new PD solutions, and pharmaceutical agents need to be tested before their implementation in the daily clinical practice. Research on humans could probably provide the necessary answers to the aforementioned topics, but it is complicated with many technical problems and ethical concerns (Stojimirovic et al., 2007). The scientific community in order to overcome this problem has exploited the observed similarities among humans and animal models. More precisely, the similar transport properties of solute and water across the peritoneal membrane in humans and animal models was an important foundation for the conduction of series of experiments in a variety of animal models.

Small animals such as rats, rabbits, and genetically modified mice have mostly been used for experimental models, although larger animals such as dogs, sheep, or even kangaroos have been used, as well. The use of each animal model comes with different advantages and disadvantages (Table 1). More precisely, rats are easy to breed and affordable, but have a short life expectancy, small size that increases the risk of complications during the insertion of a peritoneal catheter and large size of peritoneal membrane when at the same time only small quantities of dialysate can be introduced in their peritoneal cavity (Lameire et al., 1998). On the other hand, rabbits have a longer life expectancy, can survive longer on PD and the insertion of the peritoneal catheter is easier, 
TABLE 1 | Main advantages and disadvantages of different animals used in animal models.

\begin{tabular}{|c|c|c|c|}
\hline Animals & & Advantages & Disadvantages \\
\hline \multirow[t]{3}{*}{ Small } & Rats & $\begin{array}{l}\text { - Easy and affordable breeding } \\
\text { - Fast generation and maturation }\end{array}$ & $\begin{array}{l}\text { - Short life expectancy } \\
\text { - Small size-increased risk of complications } \\
\text { - Higher ratio of peritoneal surface area compared to humans } \\
\text { - Large size of parietal peritoneum } \\
\text { - High intraperitoneal amylase levels }\end{array}$ \\
\hline & Rabbits & $\begin{array}{l}\text { - Adequate life expectancy } \\
\text { - Adequate survival on PD } \\
\text { - Easy peritoneal catheter insertion } \\
\text { - Similar size of parietal peritoneum to humans } \\
\text { - Similar ratio of peritoneal surface area to humans }\end{array}$ & - Delicate animals - difficult to breed \\
\hline & $\begin{array}{l}\text { Genetically } \\
\text { modified mice }\end{array}$ & $\begin{array}{l}\text { - Easy and affordable breeding } \\
\text { - Fast generation and maturation } \\
\text { - Ability to explore the role of single proteins }\end{array}$ & - Extremely small size \\
\hline Large & $\begin{array}{l}\text { Dogs } \\
\text { Sheep } \\
\text { Kangaroos } \\
\text { etc }\end{array}$ & $\begin{array}{l}\text { - Long life expectancy } \\
\text { - Easy peritoneal catheter insertion }\end{array}$ & $\begin{array}{l}\text { - Difficult and expensive breeding } \\
\text { - Large time frame for obtaining results }\end{array}$ \\
\hline
\end{tabular}

but are very delicate animals and difficult to breed (Garosi and Di Paolo, 2001). Regarding larger animals, their life expectancy is long and could approximate PD on humans, but their breeding is difficult and expensive and a large time frame is needed for results to be obtained (Van Biesen et al., 2006).

As for the genetically modified mice, both knockout and transgenic models have been used over the past few years in order to provide important information in many different molecular pathways that are significant for PD (Nishino et al., 2007). The ability to modify the genome of mice enabled the scientists to explore the expression of different genes and the results of the modification of their expression. The role of single proteins such as aquaporin-1 in the transport of water across the peritoneal membrane (Yang et al., 1999; Ni et al., 2006) or NOS (Nitric oxide synthase) isoforms in peritonitis (Ni et al., 2010), as well as, IL-6 in inflammation (Hurst et al., 2001; McLoughlin et al., 2004) and TGF- $\beta$ in encapsulating peritonitis (Park et al., 2008) were explored using genetically modified mice. The extremely small size of these animal makes manipulations difficult ( $\mathrm{Ni}$ et al., 2003), but over the past few years the development of new molecular techniques provide significant tools to overcome this disadvantage (Devuyst et al., 2010).

Acute and chronic animal models have been developed (Hoff, 2005; Pawlaczyk et al., 2015) (Table 2). Acute models describe experiments that have short duration and can study the impact of a single dwell on the peritoneal membrane. They provide crucial information regarding mainly the transport characteristics of the peritoneal membrane and its function. Its permeability to water and solute, the interaction with different dialysis solutions, certain substances, therapeutic agents or even inflammation mediators can be extensively studied this way. On the other hand, chronic models can evaluate the chronic impact of PD resembling the impact of the method on humans due to the longer duration of the experiments. They can focus on changes of the structure and the function of the peritoneal membrane. For example, the effect of glucose used as an osmotic agent in dialysis solutions or the effect of the newer biocompatible solutions with lower GDPs' (Glucose degradation products) concentration, neutral $\mathrm{pH}$ or replacement of glucose with icodextrin on the morphology of the peritoneal membrane can be analyzed. Fibrosis, encapsulating peritoneal sclerosis, repeated episodes of peritonitis, and morphological alterations can be in depth studied using the chronic models. In this way, an important background for targeted therapeutic interventions is provided.

In the acute model the animal is anesthetized, a temporary catheter is inserted in the peritoneal cavity and during a 4-h dwell samplings of the peritoneal fluid and blood are obtained (Lameire et al., 1998). In the chronic model, on the other hand, three are the most common methods used (Mortier et al., 2005). The first method includes the direct blind injection of the dialysate into the peritoneal cavity with or without anesthesia. The repeated injections are related to increased risk of intraperitoneal bleeding and infection that could probably interfere with the results of the experiment. The second method is called "open system" and is characterized by the subcutaneous insertion of a permanent indwelling peritoneal catheter from the neck to the peritoneal cavity of the animal. This catheter can be used for the introduction of dialysate into the peritoneal cavity and the drain of the dwell directly or indirectly as it can be used as the tunnel through which another sterile catheter is inserted during every exchange. In this method anesthesia is not required but the rate of peritonitis episodes remains high and the malfunction of the catheter as a result of omental wrapping, adhesions and fibrosis is frequent. Finally, the third method is called "closed system." In this method, as in the "open-system," a permanent indwelling peritoneal catheter is inserted subcutaneously from the neck to the peritoneal cavity of the animal. The catheter is attached to a subcutaneous reservoir in the neck of the animal and the dialysate remains in the peritoneal cavity until it is fully absorbed. This method results in lower rates of peritonitis, 
TABLE 2 | The main studied parameters in acute and chronic animal models.

\begin{tabular}{|c|c|c|}
\hline $\begin{array}{l}\text { Animal } \\
\text { models }\end{array}$ & Studied parameters & \\
\hline Acute & $\begin{array}{l}\text { Transport characteristics and } \\
\text { function of the PM }\end{array}$ & $\begin{array}{l}\text { Permeability to water and solutes } \\
\text { Lymphatic drainage } \\
\text { Interaction with different dialysis } \\
\text { solutions } \\
\text { Acute effect of glucose } \\
\text { Inflammatory response-effect of } \\
\text { inflammation mediators } \\
\text { Interaction with various therapeutic } \\
\text { agents }\end{array}$ \\
\hline Chronic & $\begin{array}{l}\text { Changes of structure and } \\
\text { function of the PM }\end{array}$ & $\begin{array}{l}\text { Effect of biocompatible solutions } \\
\text { (lower GDP and neutral pH) } \\
\text { Effect of icodextrin } \\
\text { Peritonitis - defense mechanisms } \\
\text { Mesothelial cell damage } \\
\text { PM thickness } \\
\text { Vascular alterations } \\
\text { Fibrosis } \\
\text { Encapsulating peritoneal sclerosis } \\
\text { Therapeutic interventions }\end{array}$ \\
\hline
\end{tabular}

PM, peritoneal membrane.

although the malfunction of the catheter still remains a problem.

In any case, even if it is tempting, before applying the extrapolated results of animal models in humans we should point out the differences between these models and humans and the related technical problems. The most important differences concern the visceral, parietal and diaphragm surfaces. It seems that the diaphragm, which is directly related to the lymphatic drainage responsible for the clearance of macromolecules, extends to a larger area in humans than in animal models (Pawlaczyk et al., 2015). On the other hand, the parietal peritoneum that is directly related to the solute transport is larger in rats than in humans, while in rabbits it is similar to humans (Pawlaczyk et al., 1996). Moreover, it is known that the intraperitoneal levels of amylase that are elevated in rats can locally degrade icodextrin, an osmotic agent used in several dialysis fluids, rapidly (de Waart et al., 2001). To these differences one must add the higher ratio of peritoneal surface area to dialysate that is observed in rats, while in rabbits it is similar to the one observed in humans (Stojimirovic et al., 2007). Finally, in rats changes in the permeability and the surface area of the peritoneal membrane are encountered as they grow up, resulting in changes in the kinetics of the peritoneal membrane (Kuzlan et al., 1997). As Van Biesen et al highlights multiple experiments in different animal models and comparison of the results obtained could overcome those differences and provide a more realistic approach of the mechanisms that characterize PD in humans (Van Biesen et al., 2006).

Among the technical problems that have to be faced when handling animal models, tissue-sampling problems must be highlighted. The peritoneal tissue is quite fragile, dries quickly when exposed to the air and can easily be damaged even after delicate contact with surgical gloves or instruments (Duman and Sen, 2009). Furthermore, in patients on PD the visceral peritoneum exhibits more pronounced alterations than the parietal peritoneum, while in many of the studies conducted in animal models the biopsy samples are obtained by the parietal peritoneum. This inconsistency could be misleading if extrapolating results of animal studies to humans.

Catheter obstruction, peritonitis, and anesthesia use represent other major problems. In an attempt to minimize catheter dysfunction, omentectomy, and heparin have been used, but both methods have important pitfalls. On one hand the omentum is considered to be an important immune defense organ of the peritoneal cavity (Beelen, 1992), while on the other heparin is known to have many pleiotropic actions besides being an anticoagulant (De Vriese et al., 2001; Gozdzikiewicz et al., 2009). Therefore, both of these interventions could result in undesirable functional and morphological changes in the peritoneum (Mortier et al., 2005). The use of heparin coated catheters that has been suggested seems to be a good solution, since it reduces the rate of malfunction without inducing changes in the peritoneum (De Vriese et al., 2002). Regarding peritonitis, many investigators have administered antibiotics in order to prevent infections, an intervention that has been proven successful and simultaneously not leading to morphological and function changes in the peritoneum (Mortier et al., 2003; Choi et al., 2006). Finally, the use of anesthesia when handling animals has been related to changes in the peritoneum kinetics, probably through a direct reduction of the lymphatic drainage (Tran et al., 1993) and an increase of ultrafiltration and decrease of the absorption rates from the peritoneal membrane (Shin et al., 2006).

There are some important differences in animal model studies (Mortier et al., 2005; Topley, 2005). There are differences related to the volume of dialysate instilled and the time it remains in the peritoneal cavity, the frequency of the exchanges, and the total time the animals undergo PD before the termination of the study. The drainage of the dialysate is also an issue. More precisely, there are animal models characterized by the presence of the dialysate in the peritoneal cavity until it is fully absorbed, while in other animal models drainage after every dwell is performed. The last model resembles chronic PD in humans and offers the ability to better understand transportation through the peritoneal membrane and at the same time examine the dialysate for the presence of cells and substances (Pawlaczyk et al., 2015). Moreover, differences in the use of anesthesia, heparin or even the definition of peritonitis have been described. A common finding in most studies is the use of high concentration glucose solutions although in humans other lower glucose concentration solutions may also be used. Finally, the high rate of dropout due to catheter malfunction must be highlighted. It is obvious that there are many limitations when analyzing the results of the studies conducted on animal models, nevertheless the information they provide are very important and necessary to better understand this method of renal replacement therapy.

One field of special interest for nephrologists is encapsulating peritoneal sclerosis (EPS) which is a rare but life threatening complication of PD. Several animal models have been used 
in order to understand the underlying pathophysiological mechanisms that lead to EPS (Hoff, 2005; Park et al., 2008; Hirahara et al., 2015). Chlorexidine and acidic dialysis solutions, povidone iodine, formaldehyde, and even bleach and talc are some of the agents that have been used in an attempt to induce peritoneal injury and development of EPS in animal models. At the same time many different inhibitors of inflammation, angiogenesis, and fibrosis, as well as, inhibitors of the renin angiotensin system have been studied as potential therapeutic interventions in an attempt to resolve EPS (Kitamura et al., 2014).

The in vivo animal models provide useful information for future PD solutions that are yet to be tested or promote our understanding of their effects on the peritoneal membrane of ESRD patients undergoing $\mathrm{PD}$. To this end an ex vivo sheep and human model of the peritoneal ionic and water permeability can further provide useful information that can be applied in the PD solution improvement and development area (Liakopoulos et al., 2006, 2009). In these studies the membrane specimens are mounted in the Ussing System that measures the transmembrane ionic permeability (Zarogiannis et al., 2004; Stefanidis et al., 2005). The majority of such investigations involved electrophysiological experiments in sheep visceral or

\section{References}

Beelen, R. H. (1992). Role of omental milky spots in the local immune response. Lancet 339, 689. doi: 10.1016/0140-6736(92)90857-Y

Choi, J., Credit, K., Henderson, K., Deverkadra, R., Vanpelt, H. M., He, Z., et al. (2006). Antibiotic prophylaxis in an animal model of chronic peritoneal exposure. Perit. Dial. Int. 26, 249-258.

De Vriese, A. S., Mortier, S., Cornelissen, M., Palmans, E., Vanacker, N. J., Leyssens, A., et al. (2002). The effects of heparin administration in an animal model of chronic peritoneal dialysate exposure. Perit. Dial. Int. 22, 566-572.

De Vriese, A. S., Mortier, S., and Lameire, N. H. (2001). Non anticoagulant effects of heparin: implications for animal models of peritoneal dialysis. Perit. Dial. Int. 21(Suppl. 3), S354-S356.

Devuyst, O., Margetts, P. J., and Topley, N. (2010). The pathophysiology of the peritoneal membrane. J. Am. Soc. Nephrol. 21, 1077-1085. doi: 10.1681/ASN.2009070694

de Waart, D. R., Zweers, M. M., Struijk, D. G., and Krediet, R. T. (2001). Icodextrin degradation products in spent dialysate of CAPD patients and the rat, and its relation with dialysate osmolality. Perit. Dial. Int. 21, 269-274.

Duman, S., and Sen, S. (2009). Technical aspects in studying peritoneal morphology in animal models of peritoneal dialysis. Perit. Dial. Int. 29(Suppl. 2), S40-S44.

Garosi, G., and Di Paolo, N. (2001). The rabbit model in evaluating the biocompatibility in peritoneal dialysis. Nephrol. Dial. Transplant 16, 664-665. doi: $10.1093 / \mathrm{ndt} / 16.3 .664$

Gozdzikiewicz, J., Borawski, J., and Mysliwiec, M. (2009). Pleiotropic effects of heparin and heparinoids in peritoneal dialysis. Clin. Appl. Thromb. Hemost. 15, 92-97. doi: 10.1177/1076029607304722

Hirahara, I., Sato, H., Imai, T., Onishi, A., Morishita, Y., Muto, S., et al. (2015). Methylglyoxal induced basophilic spindle cells with podoplanin at the surface of peritoneum in rat peritoneal dialysis model. Biomed Res. Int. 2015:289751. doi: $10.1155 / 2015 / 289751$

Hoff, C. M. (2005). Experimental animal models of encapsulating peritoneal sclerosis. Perit. Dial. Int. 25(Suppl. 4), S57-S66.

Hurst, S. M., Wilkinson, T. S., Mcloughlin, R. M., Jones, S., Horiuchi, S., Yamamoto, N., et al. (2001). Il-6 and its soluble receptor orchestrate a temporal parietal peritoneum specimens and some of the results have been tested in human specimens yielding identical findings, thus rendering this model a powerful tool for PD solution assessment as to the ion and water transport drug induced alterations (Zarogiannis et al., 2005, 2007; Stefanidis et al., 2007). The focus of these electrophysiological investigations was the identification of ion channels, as well as, hormonal receptors present in the mesothelial compartment of the peritoneum (Kourti et al., 2007, 2013; Zarogiannis et al., 2007; Karioti et al., 2008, 2009). Most of these findings remain yet to be investigated in human specimens and subsequently tested in in vivo animal models.

In conclusion, in vivo and ex vivo animal models have been extensively used for the understanding of the properties of the peritoneal membrane and results of these experiments have been extrapolated in humans. For the time being, the fundamental differences in the animal models used, as already described, remains the main problem when it comes to comparing results of different models and especially using these results in order to evaluate the use of PD in humans. At the same time, the necessity of in depth understanding of PD brings into perspective the importance of establishing standardized protocols that could overcome the aforementioned differences and obstacles. switch in the pattern of leukocyte recruitment seen during acute inflammation Immunity 14, 705-714. doi: 10.1016/S1074-7613(01)00151-0

Jain, A. K., Blake, P., Cordy, P., and Garg, A. X. (2012). Global trends in rates of peritoneal dialysis. J. Am. Soc. Nephrol. 23, 533-544. doi: 10.1681/ASN.2011060607

Karioti, A., Hatzoglou, C., Zarogiannis, S., Deligiorgi, T., Kourti, P., Giannopoulou, M., et al. (2009). Spironolactone increases permeability of visceral sheep peritoneum. Adv. Perit. Dial. 25, 16-19.

Karioti, A., Hatzoglou, C., Zarogiannis, S., Deligiorgi, T., Liakopoulos, V., Kourti, P., et al. (2008). Rapid effect of dexamethasone on the permeability of visceral sheep peritoneum. Adv. Perit. Dial. 24, 2-6.

Kitamura, M., Nishino, T., Obata, Y., Ozono, Y., Koji, T., and Kohno, S. (2014). New insights into therapeutic strategies for the treatment of peritoneal fibrosis: learning from histochemical analyses of animal models. Acta Histochem. Cytochem. 47, 133-143. doi: 10.1267/ahc.14025

Kourti, P., Zarogiannis, S., Liakopoulos, V., Hatzoglou, C., Giannopoulou, M., Chronopoulou, I., et al. (2007). Effect of endothelin-1 on the transmesothelial resistance of isolated visceral sheep peritoneum. Adv. Perit. Dial. 23, 38-42.

Kourti, P., Zarogiannis, S. G., Liakopoulos, V., Karioti, A., Eleftheriadis, T., Hatzoglou, C., et al. (2013). Endothelin-1 acutely reduces the permeability of visceral sheep peritoneum in vitro through both endothelin-A and endothelinB receptors. Artif. Organs 37, 308-312. doi: 10.1111/j.1525-1594.2012.01565.x

Kuzlan, M., Pawlaczyk, K., Wieczorowska-Tobis, K., Korybalska, K., Breborowicz, A., and Oreopoulos, D. G. (1997). Peritoneal surface area and its permeability in rats. Perit. Dial. Int. 17, 295-300.

Lameire, N., Van Biesen, W., Van Landschoot, M., Wang, T., Heimbürger, O., Bergström, J., et al. (1998). Experimental models in peritoneal dialysis: a European experience. Kidney Int. 54, 2194-2206. doi: 10.1046/j.15231755.1998.00179.x

Liakopoulos, V., Zarogiannis, S., Hatzoglou, C., Kourti, P., Poultsidi, A., Eleftheriadis, T., et al. (2006). Inhibition by mercuric chloride of aquaporin-1 in the parietal sheep peritoneum: an electrophysiologic study. Adv. Perit. Dial. $22,7-10$.

Liakopoulos, V., Zarogiannis, S., Kourti, P., Hatzoglou, C., Karioti, A., Arampatzis, S., et al. (2009). Effect of cimetidine on the electrophysiologic profile of isolated visceral sheep peritoneum. Adv. Perit. Dial. 25, 20-23. 
McLoughlin, R. M., Hurst, S. M., Nowell, M. A., Harris, D. A., Horiuchi, S., Morgan, L. W., et al. (2004). Differential regulation of neutrophil-activating chemokines by IL-6 and its soluble receptor isoforms. J. Immunol. 172, 5676-5683. doi: 10.4049/jimmunol.172.9.5676

Mortier, S., De Vriese, A. S., Leyssens, A., Vanacker, N. J., Faict, D., Cornelissen, M., et al. (2003). Antibiotic administration in an animal model of chronic peritoneal dialysate exposure. Perit. Dial. Int. 23, 331-338.

Mortier, S., Lameire, N. H., and De Vriese, A. S. (2005). Animal models in peritoneal dialysis research: a need for consensus. Perit. Dial. Int. 25, 16-24.

Ni, J., McLoughlin, R. M., Brodovitch, A., Moulin, P., Brouckaert, P., Casadei, B., et al. (2010). Nitric oxide synthase isoforms play distinct roles during acute peritonitis. Nephrol. Dial. Transplant 25, 86-96. doi: 10.1093/ndt/gfp415

Ni, J., Moulin, P., Gianello, P., Feron, O., Balligand, J. L., and Devuyst, O. (2003). Mice that lack endothelial nitric oxide synthase are protected against functional and structural modifications induced by acute peritonitis. J. Am. Soc. Nephrol. 14, 3205-3216. doi: 10.1097/01.ASN.0000099382.18284.57

Ni, J., Verbavatz, J. M., Rippe, A., Boisdé, I., Moulin, P., Rippe, B., et al. (2006). Aquaporin-1 plays an essential role in water permeability and ultrafiltration during peritoneal dialysis. Kidney Int. 69, 1518-1525. doi: 10.1038/sj.ki.5000285

Nishino, T., Ni, J., and Devuyst, O. (2007). Transgenic mouse models. Perit. Dial. Int. 27, 625-633.

Park, S. H., Kim, Y. L., and Lindholm, B. (2008). Experimental encapsulating peritoneal sclerosis models: pathogenesis and treatment. Perit. Dial. Int. 28(Suppl. 5), S21-S28.

Pawlaczyk, K., Baum, E., Schwermer, K., Hoppe, K., Lindholm, B., and Breborowicz, A. (2015). Animal models of peritoneal dialysis: thirty years of our own experience. Biomed Res. Int. 2015: 261813. doi: 10.1155/2015/261813

Pawlaczyk, K., Kuzlan, M., Wieczorowska-Tobis, K., Pawlik-Juzków, H., Breborowicz, A., Knapowski, J., et al. (1996). Species-dependent topography of the peritoneum. Adv. Perit. Dial. 12, 3-6.

Putnam, T. (1923). The living peritoneum as a dialyzing membrane. Am. J. Physiol. $63,548-565$

Shin, S. K., Kamerath, C. D., Gilson, J. F., and Leypoldt, J. K. (2006). Effects of anaesthesia on fluid and solute transport in a C57BL6 mouse model of peritoneal dialysis. Nephrol. Dial. Transplant 21, 2874-2880. doi: $10.1093 / \mathrm{ndt} / \mathrm{gfl} 368$

Stefanidis, I., Liakopoulos, V., Kourti, P., Zarogiannis, S., Poultsidi, A., Mertems, P. R., et al. (2007). Amiloride-sensitive sodium channels on the parietal human peritoneum: evidence by ussing-type chamber experiments. ASAIO J. 53, 335-338. doi: 10.1097/MAT.0b013e3180317908
Stefanidis, I., Zarogiannis, S., Hatzoglou, C., Liakopoulos, V., Kourti, P., Poultsidi, A., et al. (2005). Enhancement of the transmesothelial resistance of the parietal sheep peritoneum by epinephrine in vitro: ussing-type chamber experiments. Artif. Organs 29, 919-922. doi: 10.1111/j.1525-1594.2005.00157.x

Stojimirovic, B., Trbojevic-Stankovic, J., and Nesic, D. (2007). Animal models in peritoneal dialysis. Scand J. Lab. Anim. Sci. 34, 283-289.

Topley, N. (2005). Animal models in peritoneal dialysis: more questions than answers? Perit. Dial. Int. 25, 33-34.

Tran, L., Rodela, H., Abernethy, N. J., Yuan, Z. Y., Hay, J. B., Oreopoulos, D., et al. (1993). Lymphatic drainage of hypertonic solution from peritoneal cavity of anesthetized and conscious sheep. J. Appl. Physiol. (1985) 74, 859-867.

Van Biesen, W., Vanholder, R., and Lameire, N. (2006). Animal models in peritoneal dialysis: a story of kangaroos and ostriches. Perit. Dial. Int. 26, 571-573.

Yang, B., Folkesson, H. G., Yang, J., Matthay, M. A., Ma, T., and Verkman, A. S. (1999). Reduced osmotic water permeability of the peritoneal barrier in aquaporin-1 knockout mice. Am. J. Physiol. 276, C76-C81.

Zarogiannis, S., Kourti, P., Hatzoglou, C., Liakopoulos, V., Poultsidi, A. Gourgoulianis, K., et al. (2005). Influence of the sodium transport inhibition by amiloride on the transmesothelial resistance of isolated visceral sheep peritoneum. Adv. Perit. Dial. 21, 5-8.

Zarogiannis, S., Liakopoulos, V., Hatzoglou, C., Kourti, P., Vogiatzidis, K., Potamianos, S., et al. (2007). Effect of sodium-potassium pump inhibition by ouabain on the permeability of isolated visceral sheep peritoneum. Adv. Perit. Dial. 23, 43-47.

Zarogiannis, S., Stefanidis, I., Hatzoglou, C., Liakopoulos, V., Gourgoulianis, K., and Molyvdas, P. A. (2004). Effect of adrenaline on the electrophysiologic profile of isolated visceral sheep peritoneum. Adv. Perit. Dial. 20, 23-26.

Conflict of Interest Statement: The authors declare that the research was conducted in the absence of any commercial or financial relationships that could be construed as a potential conflict of interest.

Copyright (C) 2015 Nikitidou, Peppa, Leivaditis, Eleftheriadis, Zarogiannis and Liakopoulos. This is an open-access article distributed under the terms of the Creative Commons Attribution License (CC BY). The use, distribution or reproduction in other forums is permitted, provided the original author(s) or licensor are credited and that the original publication in this journal is cited, in accordance with accepted academic practice. No use, distribution or reproduction is permitted which does not comply with these terms. 